\title{
FOREST DISTURBANCE DETECTION BY LANDSAT-BASED NDVI TIME SERIES FOR AYUQUILA RIVER BASIN, JALISCO, MEXICO
}

\author{
Y. Gao ${ }^{1, *}$, A. Quevedo ${ }^{1}$, J. Loya ${ }^{1}$ \\ ${ }^{1}$ Centro de Investigaciones en Geografía Ambiental, Universidad Nacional Autónoma de México, 58190 Morelia, México - \\ (ygao@ciga.unam.mx, alequech@gmail.com,jaimeloya@gmail.com)
}

KEY WORDS: Deforestation, Forest degradation, Magnitude of change

\begin{abstract}
:
Time series data have been applied for forest disturbance detection. The validation of detected changes is challenging partially because the validation data are often not readily available. Unlike multi-temporal change analysis, time series analysis not only detects areas of change but also reports time of change. Both spatial and temporal accuracy are therefore important for the accuracy assessment. Ayuquila River Basin (ARB) is one of the early action areas in Mexico for the implementation of REDD+ initiatives under UNFCCC. In ARB, shifting cultivation and cattle grazing often take place, resulting in degraded forestland. Sub-annual forest disturbance detection and estimation contribution to the improved local forest management and REDD+ implementation. Landsat-based NDVI time series data covering 1999-2018 were analysed using linear regression and the breakpoints of change and the magnitude of change were detected. Breakpoints with magnitude of change ranging from (-0.05) to (-0.2) were verified during a field campaign in October 2018. Here the magnitude of change is related with NDVI differences. Areas with magnitude of change higher than (-0.2) were identified as false changes. Verification data were generated by visually interpreting time series Landsat images of 2016-2018. In this way, areas with forest loss were identified. By stratified random sampling, 683 points were applied for the verification including 511 points of forests and 172 points of forest loss. It yields $75.84 \%$ for the overall accuracy of the change detection; for the detected forest loss as a category, the user's accuracy is $88.89 \%$ and the producer's accuracy is $0.46 \%$. A possible reason for the very low producer's accuracy is that the selected magnitude value $(-0.2)$ is too low and some of the detected changes were filtered out.
\end{abstract}

\section{INTRODUCTION}

\subsection{Background}

Forest disturbance is an important source of greenhouse gas (GHG) emission and contributes to global temperature rise and climate change. The UNFCCC initiative REDD+ combats climate change by reducing GHG through reducing deforestation and forest degradation. Ayuquila River Basin (ARB) is one of the "Early Action Areas" for implementation of REDD+ in Mexico. Tropical dry forest in ARB is going through degradation by disturbances including slash and burn agriculture practices, cattle grazing, extraction of poles and forest fires. A timely disturbance detection is important to take effective actions and make management plans work. Multi-temporal change detection methods have been carried out in ARB (Ghilardi et al. 2012). However, temporally dense satellite image observation detects forest thinning before a clear-cutting as it may need a few weeks to finish.

Forest degradation has been studied by trajectory-based analysis with time series data (Banskota et al., 2014). Annual composites (Huang et al., 2010) have been used in detecting long term changes, including forest regrowth (Czerwinski et al., 2014). Since annual data may underestimate the extent of forest disturbances such as from selective logging (Matricardi et al., 2005), a more frequent time series may be necessary to capture the optical signature of logging before the evidence of logging disappears (Matricardi et al., 2015; De Sy et al., 2012). Dense time series data may also be useful to capture positive changes in forest cover such as the natural recuperation and recovery that often follow degradation.
Landsat based time series data have been applied to estimate forest degradation (Hamunyela et al., 2016). Normalized Difference Vegetation Index (NDVI) was least affected by topographic factors and NDVI time series are fundamental to the remote sensing-based vegetation phenology and vegetation dynamics (Dutrieum et al. 2016).

\subsection{Hypothesis and objectives}

The hypothesis of this work is that time series Landsat NDVI is suitable for forest disturbance detection. The objective is to carry out vegetation cover change detection using temporally dense Landsat based NDVI images spanning 1990 - 2018, and to verify the accuracy of the detected vegetation cover change. This work contributes to forest degradation monitoring and to the implementation of REDD+ initiatives in Mexico.

\section{DATA, METHODS, RESULTS}

\subsection{The study area and data}

The ARB is located in western Jalisco (Figure 1). The average annual temperature is about $19^{\circ} \mathrm{C}$ and the mean annual rainfall ranges from 700 to $1000 \mathrm{~mm}$ (Gao et al., 2016). Tropical dry forest is the largest forest category covering $24 \%$ of the watershed. Pine-oak forest is the next largest forest category with approximately $12 \%$ of the coverage (Ghilardi et al. 2012). During the past 20 to 30 years, tropical dry forest and scrubland in its central part have been cleared for permanent agriculture (Morales-Barquero et al. 2014). The main drivers of forest

\footnotetext{
* Corresponding author
} 
degradation include shifting cultivation, cattle grazing, fence construction, and fires.

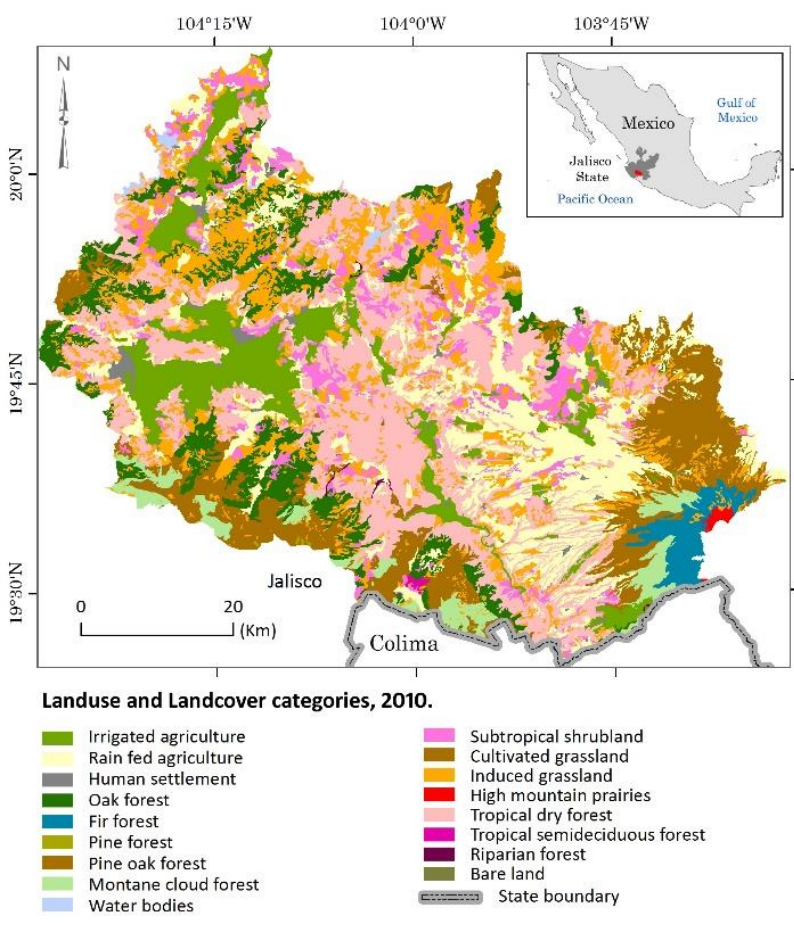

Figure 1 . The study area represented by land cover land use map of 2010, including 17 categories, interpreted from Landsat images.

Landsat data from 1990 to 2018 were collected through Google Earth Engine (GEE). NDVI images were calculated using near infrared band (NIR) and red band (RED) of Landsat images, NDVI $=($ NIR-RED $) /($ NIR+RED $)$. Images from Planet (www.planet.com) were downloaded to visually verify the detected forest cover changes. Planet images have very high spatial resolution of 3 meters with four multispectral bands (blue, green, red, and near infrared). RapidEye images are also available in Planet with a spatial resolution of $5 \mathrm{~m}$ and five spectral bands (blue, green, red, red-edge and near infrared), both types of images are collected daily.

Verification data were derived from visual interpretation of time series Landsat images from 2016 to 2018 for the two categories of "forest loss" and "forest". The design of verification data follows Cochran (1977). In total, 683 random points comprising 172 points of "forest loss" and 511 points of "forest" were used for accuracy assessment.

\subsection{Methods}

NDVI time series data were pre-processed in GEE using quality layer and fmask that are implemented in GEE to screen out the clouds and cloud shadow. BFAST spatial was applied for the change detection. The NDVI data spanning 1999-2015 were used to construct a stable reference period, and data from 2016-2018 were used for change detection. A moving sum of residuals (MOSUM) between the observed and predicted NDVI values was used to compare with the MOSUM from the reference period based on which the breakpoints of change were detected. Magnitude of change was then computed by subtracting the predicted NDVI from the observed one. To define the threshold of magnitude of change, breakpoints with magnitude of change ranging from $(-0.05)$ to $(-0.2)$ were verified during a field campaign in 15-24 October 2018, during which, forest condition at 12 locations where forest disturbance was detected by time series NDVI were evaluated, including tropical dry forest, tropical humid forest, and oak forest. Areas with false changes were identified during field campaign which corresponds to the areas which the magnitude of change higher than (-0.2). Inside Chamela forest reserve, forest disturbance were caused by natural events such as hurricane damage and post-hurricane fire. In the north of ARB, anthropogenic causes of deforestation for agave plantations were identified. An area of fire induced forest disturbance was also identified; however, the type of forest was not identifiable due to the inaccessibility. Based on the observation from field campaign, the threshold value of $(-0.2)$ was selected as the magnitude of change. The general workflow of this paper is described Figure 2.

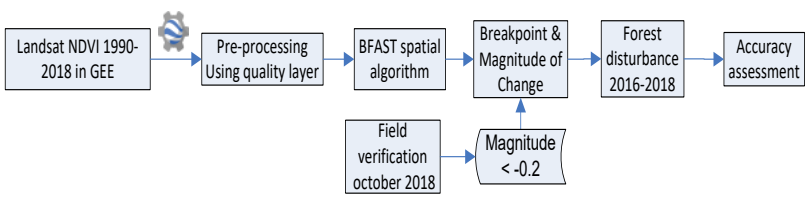

Figure 2. the general workflow of the forest disturbance detection and verification.

\subsection{NDVI values and forest disturbance}

The range of NDVI values is $(-1-1)$. Since green vegetation has strong reflectance in the NIR and weak reflectance in RED, higher positive NDVI values correspond to undisturbed green vegetation and this value decreases when vegetation is disturbed, for example, by fires. The common agriculture practices of slash and burn in this area leave some areas devoid of vegetation (tropical dry forest) for some time, usually around 3-5 years, and then the land was left to rest for another period, during which the natural vegetation recovers. When monitored by time series NDVI images, the NDVI values are expected to be stable and positive before the disturbance, and then experience a sharp drop in the moment of slash and burn, and then somehow recover during the agriculture activity. After the land was left to rest, NDVI values would expect to recover almost to the level before the disturbance. This cycle repeats when another round of slash and burn happens, and finally leaves the vegetation in a degraded state. In the case of deforestation due to cattle ranching or agave plantation, the forest area experiences a clear-cutting, and is replaced with grassland or agave plants which can be registered by the change in the NDVI time series data by a sharp drop of NDVI values comparing to the stable reference period. However, when the grassland is established, the NDVI values recover.

\subsection{Change detection}

Forest disturbance was detected using BFAST spatial. The time series Landsat NDVI data were fitted to a linear regression model using equation 1 . In this model, a harmonic function is included to consider the vegetation seasonality. BFAST identifies and models historical data automatically as the reference period (Verbesselt et al. 2012b).

$$
\left.Y_{t}=\alpha_{1}+\alpha_{1} t+\sum_{j=1}^{k} \gamma \sin \left(\frac{2 \pi \mathrm{jt}}{f}+\delta_{j}\right)+\varepsilon_{t} \quad \text { (equation } 1\right)
$$

Here $Y_{t}$ is the predicted NDVI value. $\alpha_{1}$ is the intercept by regressing the historical data with time $t$, calculated by ordinary least squares. $\alpha_{2}$ is the slope of the linear regression, and $\varepsilon_{t}$ is the random error. In the harmonic function, $\gamma$ is the amplitude, $\delta_{j}$ is 
the phase of the harmonic season, $f$ is the frequency of the observations per year and $\kappa$ is the fitted terms defined by the user. We used 23 annual observations for the Landsat NDVI time series obtained every 16 days and fitted three harmonic terms $\kappa=3$ in the model. For the change detection, the predicted NDVI value $Y_{t}$ and the observed NDVI value $y_{t}$ were compared and the residual of the model was calculated. Using equation 2 , a moving sum of the residuals was calculated.

$\mathrm{MO}_{t}=\frac{1}{\sigma \sqrt{n}} \sum_{s=t-h+1}^{t}\left(y_{s}-Y_{s}\right) \quad($ equation 2$)$

$\mathrm{MO}_{t}$ is the moving sum of the residuals, $\sigma$ is the variance estimator, $y_{s}$ is the actual observation, $Y_{s}$ is the predicted value, $n$ is the number of observations in the historical period and $h$ is the size of the moving window defined as a fraction of $\mathrm{n}$ and $\mathrm{t}$ is the time. Here we assigned $25 \%$ of the historical period as the size of the moving window. In the next step, we tested whether $\mathrm{MO}_{t}$ is significantly different from the moving sum of the residuals of the reference period MOt. A change is detected when the $\mathrm{MO}_{t}$ is significantly different from MOt and the magnitude of change is computed through the difference between the observed and the predicted NDVI value $\left(y_{s}-Y_{s}\right)$.

BFAST spatial applies the algorithm of BFAST monitor in the context of satellite images, where potentially each pixel corresponds to a time series. To detect forest disturbance, the magnitude of change of only those pixels where breakpoints occurred is considered. To avoid false positive detection, a threshold of (-0.2) was established by verifying the detected changes with field observations. Field data: tracks of field visit, characteristics of verified points for magnitude; Pixels with magnitude of change lower than this threshold were labelled as deforestation. Since this algorithm returns only one breakpoint per pixel, and only forest pixels were analysed, we assume the detected changes are results of activities that cause forest disturbance such as slash and burn, or deforestation.

By applying the threshold (-0.2) for magnitude of change, 394 patches of deforestation were detected for a period of 3 years: 2016-2018. The total area of detected forest cover loss is 5.2 $\mathrm{km}^{2}$, which is $0.23 \%$ of total area of forest in the ARB (Figure 3).

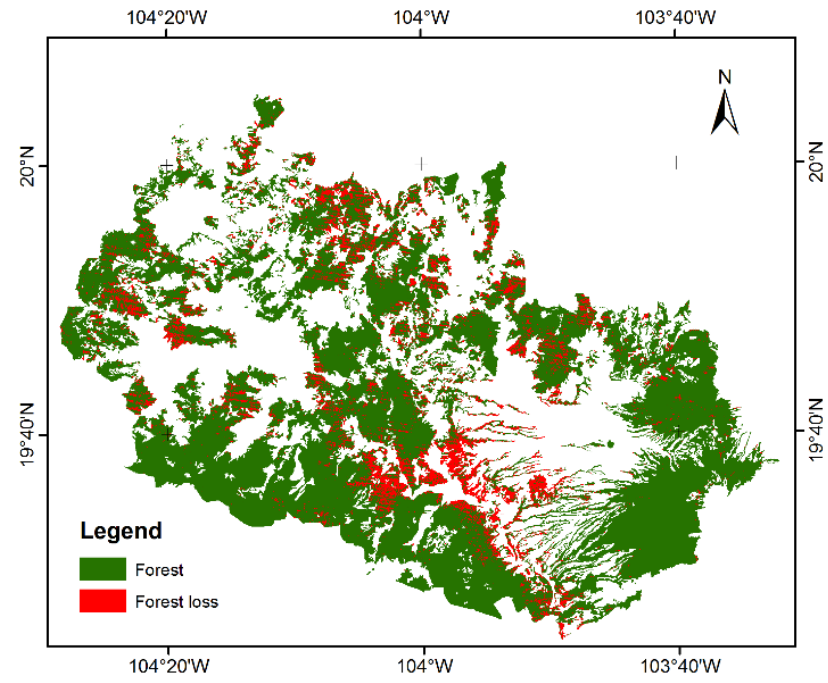

Figure 3. The detected forest loss by applying the threshold of magnitude of change (-0.2).

\subsection{Accuracy assessment}

Two methods of accuracy assessment were applied. The first one verified the detected changes visually with high resolution images from Planet (www.planet.com). We randomly selected 51 patches of change which is about $15 \%$ of the total changes to go through validation. High spatial resolution images before and after the changes were compared. 35 patches $(68.1 \%)$ were verified correctly, and therefore there is about $32 \%$ error is the commission error. However, no omission error can be reported by this method.

The second method verified the accuracy using verification data including two categories: forest loss and forest which were derived from visual interpretation of time series Landsat images from 2016-2018. Afterwards, a stratified random sampling method was applied to extract random points for the verification. The size of the samples was determined after Cochran (1977) using the following equation:

$$
n=\left[\left(\frac{z}{m}\right)^{2}\right] \times p \times(1-p)
$$

where $\mathrm{z}$ is the standard deviation according to the established level of confidence, in this case 1.96 for $95 \%$ of the confidence level, $\mathrm{m}$ is the margin of the error $(0.03)$, and $\mathrm{p}$ is the proportion of the assumed population, in this case $(0.8)$.

$$
n=\left[\left(\frac{1.96}{0.03}\right)^{2}\right] \times 0.8 \times(1-0.8)=683
$$

And then we estimated the sample size for both forest and forest loss after Czaplewski (2003).

$$
n_{i}=\left[p_{i} \times(n / 2)+\left(\frac{1}{k}\right)\left(\frac{n}{2}\right)\right]
$$

where $n_{i}$ is the sample size for the mapped stratum $i, n$ is the total sample size, $p_{i}$ is the proportion of the population mapping in category $i$, and $k$, is the total mapped categories. In this case, the total number of pixels per category is considered (Table 1).

Table 1. Total detected changes and sample sizes.

\begin{tabular}{l|l|l|l|l}
\hline Category & $\begin{array}{l}\text { Number of } \\
\text { pixels }\end{array}$ & Area $\left(\mathrm{km}^{2}\right)$ & Percentage & $\begin{array}{l}\text { Sample } \\
\text { size }\end{array}$ \\
\hline $\begin{array}{l}\text { Forest } \\
\text { Forest loss }\end{array}$ & 2442980 & 2198.682 & 99.68 & 511 \\
Total & 2450659 & 6.911 & 0.31 & 172 \\
6205.593 & 1 & 683 \\
\hline$n_{i}$ & $=\left[0.9968 \times(683 / 2)+\left(\frac{1}{2}\right)\left(\frac{683}{2}\right)\right]=511$ \\
$n_{2}$ & $=\left[0.0031 \times(683 / 2)+\left(\frac{1}{2}\right)\left(\frac{683}{2}\right)\right]=172$
\end{tabular}

For the accuracy assessment, we applied the method proposed by Card (1982) and Olofsson et al. (2014), which allow the correction of the bias due to the proportion of the categories in the map. The correction of the bias was through a plugin in Qgis (Mas et al. 2014). The results of the accuracy assessment are presented in table 2 . Within 172 points of forest loss, only 8 points were correctly identified, which shows huge omission error of disturbance detection. This can be an indication that the threshold of magnitude of change of $(-0.2)$ was set too high, resulting in many detected breakpoints as non-change. 


\begin{tabular}{|l|l|l|}
\hline \multicolumn{3}{|c|}{ Confusion Matrix } \\
\hline Forest & Forest & Forest loss \\
\hline Forest loss & 510 & 164 \\
\hline \multicolumn{3}{|l|}{ Adjusted Confusion Matrix (Card Correction) } \\
\hline \multicolumn{1}{|l|}{1} & Forest & Forest loss \\
\hline Forest & 0.756 & 0.243 \\
\hline Forest loss & 0.0001 & 0.001 \\
\hline Overall Accuracy & 0.757 & \\
\hline User Accuracy & 0.757 & 0.889 \\
\hline Producer Accuracy & 0.99 & 0.005 \\
\hline
\end{tabular}

Table 2. accuracy assessment results described in error matrix.

\section{DISCUSSIONS}

\subsection{Landsat NDVI time series data}

NDVI time series data were filtered with quality layer and fmask algorithm to remove cloud and cloud shadow which left data gaps in time series data. Although by BFAST spatial, the change detection algorithm works with gaps in the time series. The future topic is to find out how the number of no-data pixels (NA) in a time-series affects change detection. The data gap is a common problem for Mexico with about 4 months of raining season.

\subsection{Accuracy assessment}

To ensure a proper verification of spatial and temporal changes from time-series analysis, verification data need to be collected correctly. The case of verification with two-time change analysis results; the case with field data; obtaining verification data with Google Earth images depends on the spatial and temporal coverage of high-resolution images. The case with planet: $15 \%$ of 394 detected patches went through visual verification with high resolution images available at planet (www.planet.com). Independent verification data generated by visual interpretation of Landsat images (time consuming); A comparison with change detection by MODIS NDVI time series; scale matters

\subsection{Relate forest disturbance with forest degradation}

Forest degradation reflects a loss in biomass, forest carbon and forest services and is difficult to detect by remote sensing methods. The change detection returns forest loss; however, it is difficult to relate the loss to forest degradation. Some of the reasons include forest degradation often happens in fine scales. For example, the degradation caused by disturbances such as cattle grazing and fuelwood collection only happens under the canopy cover, invisible to optical satellites until its cumulative effects result in changes to the forest cover (Pratihast et al. 2014). With time series analysis, Defries et al. (2015) found a large spread in the relationship between probability of degradation and magnitude, both with and without breakpoints.

Several studies suggested that once a certain threshold of disturbance is reached, tropical forests may collapse or switch to an alternative stable state. Poorter et al. (2016) shows that forests can be resilient, and their biomass resilience strongly depends on water availability. Although the carbon value of tropical dry forest in ARB is low in comparison with temperate forest, it is important to conserve the tropical dry forest because of its importance in biodiversity conservation (evidence of wild animals such as deer, cheetah) and water retention, and in combating climate change. One of the useful practices is through silvo-pastoralism which combines cattle grazing with conservation of forests.

\section{CONCLUSIONS}

It is challenging to detect forest degradation with remote sensing methods. Comparing with deforestation, forest degradation involves changes to the structure of the forest and frequently happens in small areas. Time series analysis presents advantages in detecting vegetation cover change. On one hand, not severely damaged forest often recovers fast and so data with enough frequency ensures the detection of change before the evidence disappears. On the other hand, not all the open forests are degraded; time series analysis can separate degraded forest from naturally open forest. This paper presents forest disturbance detection using time series NDVI data for the Ayuquila watershed, Jalisco state, Mexico for the period of $1998-2018$. The accuracy assessment showed a $75 \%$ overall accuracy. The detected forest disturbance is mainly related with forest cover loss. The future challenge includes how to relate the detected forest disturbance to forest degradation.

\section{ACKNOWLEDGEMENTS}

The authors acknowledge the financial support from the project Conacyt SEP 285349 "Análisis del patrón especial de la degradación en selvas y bosques de México con percepción remota en múltiples escalas en el tiempo y espacio" for the field work and data análisis.

\section{REFERENCES}

Banskota, A., Kayastha, N., Falkowski, M.J., Wulder, M.A., Froese, R.E., White, J.C. (2014) Forest monitoring using Landsat time series data: a review. Canadian Journal of Remote Sensing 40, 362-384.

Card, D., 1982: Using known map category marginal frequencies to improve estimates of thematic map accuracy. Photogrammetric Engineering and Remote Sensing 48(3), 431439.

Cochran, W, G., 1977: Sampling techniques, $3^{\text {rd }}$ Edition New York: John Wiley \& Sons 428 pp.

Czaplewski, R., L., 2003: Statistical design and methodological considerations forthe accuracy assessment of maps of forest condition. In M. A. Wulder, \& S. E. Franklin (Eds.), Remote sensing of forest environments: Concepts and case studies (pp. 115-141). Boston MA: Kluwer Academic Publishers 519 pp.

Czerwinski C.J., D.J., King, S.W., Mitchell. 2014. Mapping forest growth and decline in a temperate mixed forest using temporal trend analysis of Landsat imagery, 1987-2010. Remote Sens Environ. 141:188-200.

De Sy, V.; Herold, M.; Achard, F.; Asner, G. P.; Held, A.; Kellndorfer, J.; Verbesselt, J. Synergies of multiple remote sensing data sources for REDD+ monitoring. Current Opinion Environmental Sustainability 2012, 4(6), 696-706.

DeVries, B., Decuyper, M., Verbesselt, J., Zeileis, A., Herold, M., Joseph, S. 2015. Tracking disturbance-regrowth dynamics in tropical forests using structural change detection and Landsat time series. Remote Sensing of Environment 169, 320-334. 
Dutrieux L.P., J.,Verbesselt, L. Kooistra, M., Herold. 2015. Monitoring forest cover loss using multiple data streams, a case study of a tropical dry forest in Bolivia. ISPRS Journal of Photogrammetry and remote sensing. 107:112-125.

Gao, Y., A. Ghilardi, J. Paneque-Galvez, M. Skutsch, J.F. Mas. 2016. Validation of MODIS Vegetation Continuous Fields for monitoring deforestation and forest degradation: two cases in Mexico. Geocarto International. 31(9). 1019-1031.

Huang, C., Goward, S. N., Masek, J. G., Thomas, N., Zhu, Z., Vogelmann, J. E. (2010) An automated approach for reconstructing recent forest disturbance history using dense Landsat time series stacks. Remote Sensing of Environment 114, 183-198.

Hamunyela, E., Verbesselt, J., Herold, M. (2016) Using spatial context to improve early detection of deforestation from Landsat time series. Remote Sensing of Environment 172, 126-138.

Mas, J., F., Pérez-Vega, A., Ghilardi, S., Martínez, J. O., LoyaCarrillo, and V., Ernesto. 2014. "A Suite of Tools for Assessing Thematic Map Accuracy”. Geography Journal 2014: 10 pages. https://doi.org/10.1155/2014/372349.

Matricardi, E.A.T., Skole, D.L., Cochrane, M.A., Qi, J., Chomentowski, W. 2005. Monitoring selective logging in tropical evergreen forests using Landsat: multitemporal regional analyses in Mato Grosso, Brazil. Earth Interact. 9:1-24.

Matricardi et al., 2015

Morales-Barquero, L., Skutsch, M., Jardel-Peláez, E., Ghilardi, A., Kleinn, C., Healey, J. (2014) Operationalizing the Definition of Forest Degradation for REDD+, with Application to Mexico. Forests 5, 1653-1681.

Olofsson, P., G. M., Foody, M., Herold, S. V., Stehman, C. E., Woodcock, \& M. A. Wulder. 2014. "Good practices for estimating area and assessing accuracy of land change". Remote Sensing of Environment 148: 42-57.

Poorter, L., Bongers, F., Aide, T.M., et al. 2016. Biomass resilience of Neotropical secondary forests. Nature, 530. 211214.

Pratihast, A., B., DeVeries, V., Avitabile, S., de Bruin, L., Kooistra, M., Tekle, et al. 2014. "Combining satellite data and community-based observations for forest monitoring". Forests 5: 2464-2489 